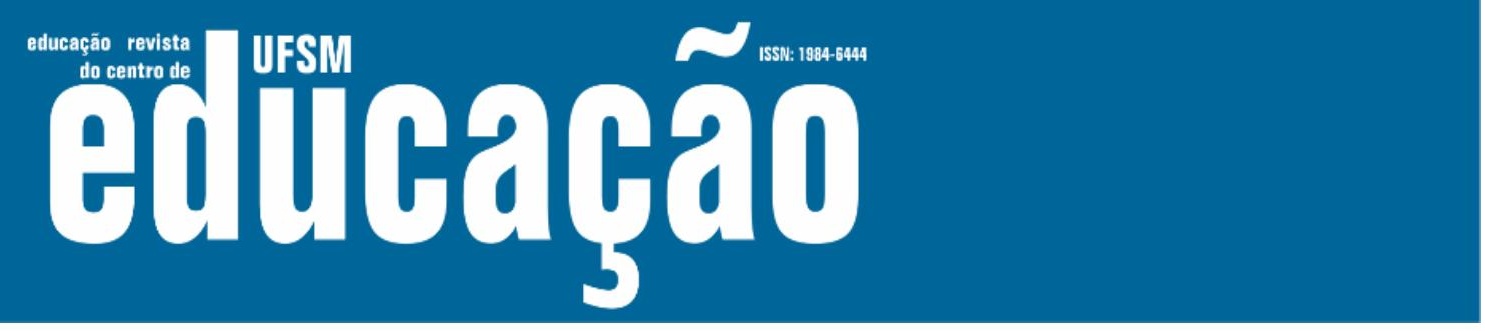

ISSN: 1984-6444 | http://dx.doi.org/10.5902/1984644438119

\title{
Leitura de história em quadrinhos: entre Shakespeare e Mauricio de Sousa'
}

\author{
Reading and comics: between Shakespeare and Mauricio de Sousa
}

\author{
Flávia Brocchetto Ramos \\ Professora doutora na Universidade de Caxias do Sul, Caxias do Sul, Rio Grande do Sul, Brasil. \\ ramos.fb@gmail.com - http://orcid.org/0000-0002-1488-0534 \\ Eliana Buffon \\ Mestra na Universidade de Caxias do Sul, Caxias do Sul, Rio Grande do Sul, Brasil. \\ eliana@promob.com - http://orcid.org/0000-0003-1110-2371 \\ Eliana Rela \\ Professora doutora na Universidade de Caxias do Sul, Caxias do Sul, Rio Grande do Sul, Brasil. \\ erela@ucs.br - http://orcid.org/0000-0001-9670-1634
}

Recebido em 12 de maio de 2019

Aprovado em 14 de novembro de 2019

Publicado em 31 de janeiro de 2021

\section{RESUMO}

A leitura de história em quadrinhos, de natureza literária, pressupõe vários desafios ao leitor iniciante de modo que as práticas educativas deveriam contemplar estratégias de mediação que atentem para as peculiaridades do gênero. Este artigo investiga a construção de uma narrativa Turma da Mônica: Romeu e Julieta, de Mauricio de Sousa (2009), selecionada pelo Programa Nacional Biblioteca da Escola (PNBE 2012). O caráter descritivo-analítico predomina no estudo e contempla aspectos visuais e verbais. Para compor a análise, são tomados aspectos do âmbito da visualidade, como tipos de quadros; cenários; marcação temporal; e, quanto aos personagens, é priorizada a sua vestimenta e a mescla entre comportamentos peculiares de Mônica e Cebolinha e de Romeu e Julieta. O estudo fundamenta-se, entre outros, em Eisner (2012), e aponta a intertextualidade como traço marcante na composição do enredo, de modo que o leitor deve ser orientado acerca de peculiaridades dos personagens de Shakespeare para potencializar a leitura da obra. Palavras-chave: História em quadrinhos; Leitura literária; Programa Nacional Biblioteca da Escola. 


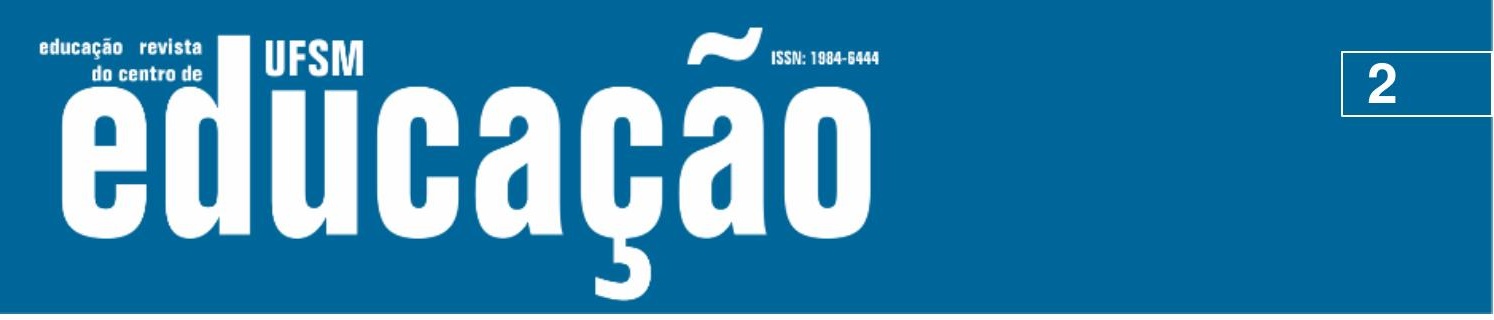

ISSN: 1984-6444 | http://dx.doi.org/10.5902/1984644438119

\section{ABSTRACT}

Comic book reading, of a literary nature, contemplates several challenges to beginner readers; in this sense, educational practices should contemplate strategies of mediation that cope with the peculiarities of the genre. This article investigates the construction of a narrative: Turma da Mônica: Romeu e Julieta, by Mauricio de Sousa (2009), selected by School Library National Program of 2012 (PNBE 2012). The descriptive-analytic character predominates in this study, which contemplates visual and verbal aspects. To compose this analysis, some aspects are taken into account, such as, in the area of visuality, kinds of frames; scenarios; temporal marking; and, as for the characters, the dress of the characters is prioritized, together with the mixture between the peculiar behavior of Monica and Cebolinha, and Romeo and Juliet. The analysis is based, among others, on Eisner (2012) and points at intertextuality as a striking feature in the composition of the plot, so that the reader should be guided by the peculiarities of the characters of Shakespeare to incentivize reading the work.

Keywords: Comic books; Literary reading; School Library National Program.

Os quadrinhos se mostram como um recurso para a compreensão do texto que se apresenta de modo híbrido na articulação entre palavras e ilustrações, neste caso, com ênfase nas imagens e nos seus elementos gráficos, pelo seu importante papel no gênero (RAMOS; PANOZZO: 2012, p. 360).

A interação com as diversas linguagens oportuniza a constituição dos sujeitos, tendo a leitura e a escrita como práticas cotidianas indispensáveis para a inserção e atuação humana no espaço social em que as pessoas vivem. Entendemos que programas de leitura como o Programa Nacional Biblioteca da Escola (PNBE) possibilitaram que muitos estudantes tivessem a oportunidade de experienciar a leitura literária desde cedo, indo ao encontro do que vislumbra Rojo quando aponta como um dos principais objetivos da escola: "[...] possibilitar que seus alunos possam participar das várias práticas sociais que se utilizam da leitura e da escrita (letramentos) na vida da cidade, de maneira ética, crítica e democrática" (2009, p. 107). Neste contexto, a leitura é uma experiência constituidora do sujeito, do seu conhecimento e dos seus saberes, e o desenvolvimento de atividades que contemplem a identidade é uma maneira de contribuir para a formação de sujeitos conscientes de seu papel social.

Os modos de se expressar a partir da linguagem vão se modificando e, consequentemente, o acervo às bibliotecas, incluindo as escolares se altera. Embora 


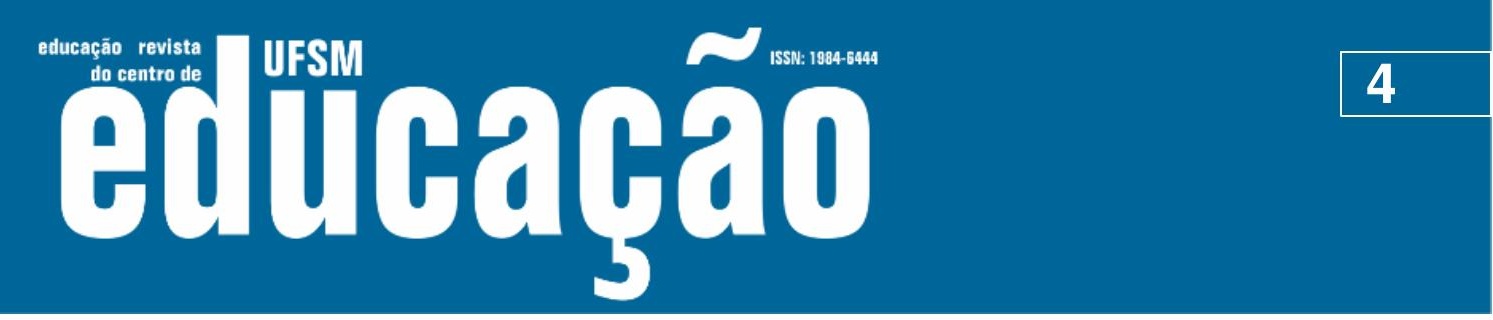

ISSN: 1984-6444 | http://dx.doi.org/10.5902/1984644438119

No ano de 2012, dentre os 100 títulos eleitos, apenas dois em quadrinhos integraram o acervo do Programa para os anos iniciais, foco de estudo desta pesquisa: Turma da Mônica: Romeu e Julieta, de Mauricio de Sousa e A Turma do Pererê - 365 dias na Mata do Fundão, de Ziraldo. As demais obras de $\mathrm{HQ}$ são direcionadas à Educação Infantil ou à EJA, como podemos verificar no Quadro1.

Quadro 1 - HQ distribuídas pelo PNBE 2012

\begin{tabular}{|l|l|l|}
\hline \multicolumn{1}{|c|}{ TITUULO } & \multicolumn{1}{|c|}{ AUTOR/EDITORA } & PÚBLICO \\
\hline O ratinho se veste & Jeff Smith /Companhia das Letrinhas & EI \\
\hline Bando de dois & Danilo Beyruth/Zarabatana Books & EJA \\
\hline Aya de Yopougon & Marguerite Abouet/Clement/L\&PM & EJA \\
\hline Frankstein & Companhia Editora Nacional & EJA \\
\hline Drácula & BramStoker/Companhia Editora Nacional & EJA \\
\hline $\begin{array}{l}\text { A turma do Pererê - 365 dias na } \\
\text { Mata do Fundão }\end{array}$ & Ziraldo/Editora Globo & EF \\
\hline Turma da Mônica: Romeu e Julieta & Mauricio de Sousa/Panini & EF \\
\hline
\end{tabular}

Fontes: MEC

Neste artigo, investiga-se a construção de Turma da Mônica: Romeu e Julieta, de Mauricio de Sousa (2009), título que compõe o acervo do PNBE 2012 - Anos Iniciais do Ensino Fundamental, a fim de apontar desafios que as $\mathrm{HQ}$ oferecem ao leitor. A obra selecionada é uma adaptação da história do dramaturgo e poeta inglês William Shakespeare, intitulada Romeu e Julieta.

\section{As origens da história}

Romeu e Julieta é um exemplo de metamorfose literária, isto é, quando uma história é contada a um determinado grupo social em um certo tempo e lugar, passado um período, algum ouvinte e apreciador daquela história, ao viajar a conta em outro cenário. Assim, a história viajante no tempo e nos espaços ganha contornos diferentes, ou o lugar onde se passa a trama é modificado, ou ainda os personagens são levados a viver experiências diferentes. Com a história de Romeu e de Julieta foi assim. A metamorfose literária produziu versões da história da romântica dupla popularizada por Shakespeare. O dramaturgo inglês publicou sua variante da trágica história dos jovens apaixonados, habitantes da cidade de Verona, na Itália, por volta 


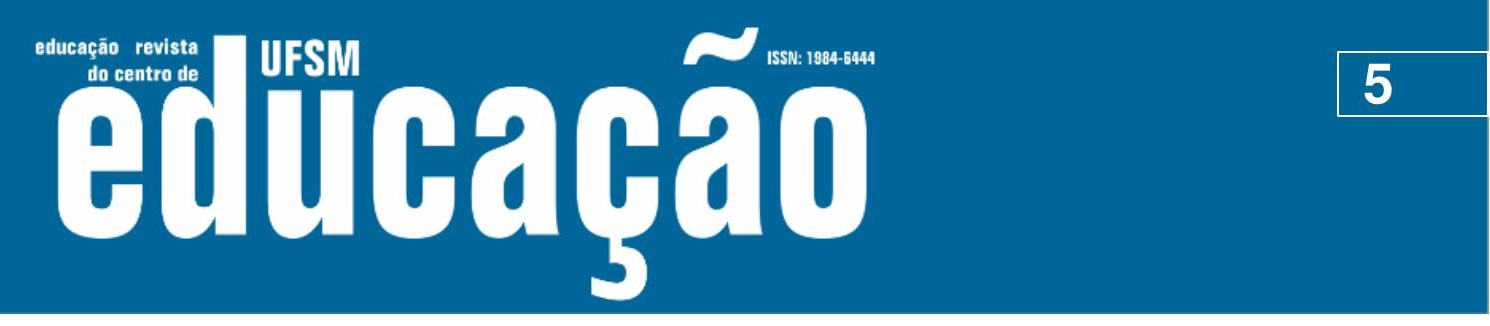

ISSN: 1984-6444 | http://dx.doi.org/10.5902/1984644438119

do ano 1596, dando a tragédia dos dois amantes um destino imortal. Mas a história existia antes de Shakespeare? Possivelmente sim, uma vez que, na Itália, durante o período que vai do século XIV ao XVI, a metamorfose literária foi prática comum.

A história foco desse estudo apresenta indícios da fusão de obras escritas por diferentes autores desde 1476, quando Masuccio Salerniano registrou o romance de Mariotto e Ganozza, ambientado em Siena, e não em Verona. A história fala de um casamento secreto, um frade amigo, da confusão na qual um cidadão principal é morto, do exílio de Mariotto, do casamento forçado da personagem Ganozza, da poção e da mensagem fundamental que se perdeu. Nesta versão, Mariotto é capturado e decapitado, a jovem apaixonada, Ganozza, morre de dor.

Francesca Fontanili textualmente informa:

Esta é a história de dois jovens amantes de uma família nobre, cujo amor nasce e os leva a encontros em segredo. Da mesma forma, o casamento se realiza em segredo com ajuda de um frade, que também interveio na aparente morte da jovem. O frade fornece um líquido fantástico com o poder de colocar em aparente estado de morte quem o ingere, mas tem o seu efeito interrompido após algum tempo. A ideia do frade foi para ajudar a jovem evitar o casamento imposto pela família no mesmo período em que Mariotto foi forçado a se afastar de Siena, refugiando-se em Alexandria, no Egito. $O$ isolamento do jovem Mariotto foi motivado pelo assassinato de um homem durante uma briga, que ele mesmo provocou. A história termina primeiro com a morte de Mariotto, que por um desencontro, não recebe uma carta na qual estava informado sobre os planos da noiva. Chegando a Siena é reconhecido e decapitado. A história termina com a morte da jovem Giannozza que se isola em um mosteiro, morrendo lentamente devido a profunda debilidade física. Assim como na tragédia de Shakespeare, o amor dos dois jovens é interrompido pelos mesmos fatos: a intervenção de um frade - tanto para realizar o casamento, como para ajudar a jovem fugir de um casamento arranjado; o tema da viagem de Mariotto que foge da cidade de Siena para Alexandria do Egito, a fim de escapar da condenação; a não entrega da carta que explica para o plano e, finalmente, a morte dos dois amantes, que se passa de forma diferente de Romeu e Julieta (FONTANILI, 2015, p. 36 tradução nossa) ${ }^{2}$.

Luigi Da Porto, natural de Vicenza (Itália), narrou sua versão de uma certa história redescoberta, de dois amantes, filhos de famílias da nobreza, com a lamentável morte do casal. Essa versão, contada a Luigi por um peregrino de Verona, já continha todos os ingredientes da tragédia shakespeariana e teria transcorrido no tempo de Bartolomeo della Scala, nobre que governou a cidade de Verona de 1301 a 1304. Quando Della Scalla assume a liderança da cidade, tentou, sem sucesso, 


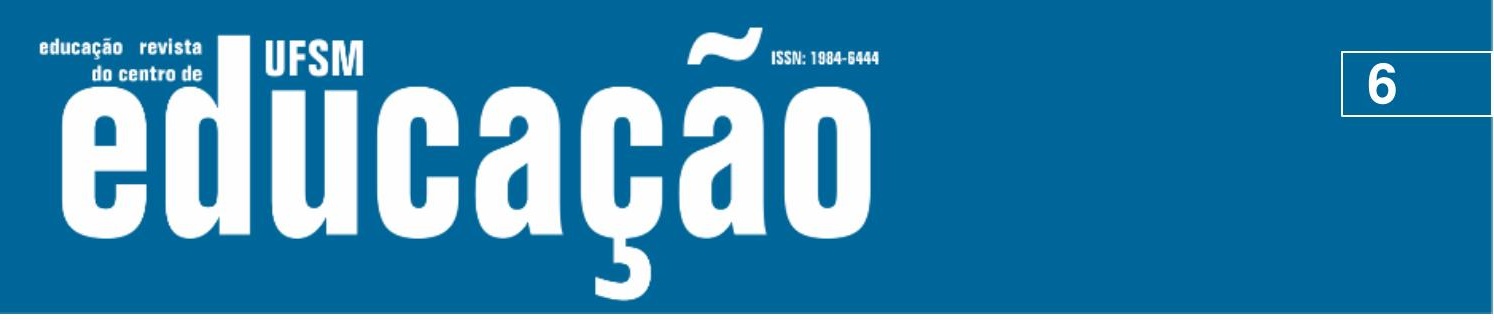

ISSN: 1984-6444 | http://dx.doi.org/10.5902/1984644438119

apaziguar o ódio e as lutas internas entre famílias locais, divididas nas facções opostas dos guelfos e gibelinos. Naqueles anos, a rivalidade concretizava-se entre a família Montecchi e Capuleti. Segundo Fontanili (2015, p. 8), os sobrenomes popularizados por Shakespeare são encontrados em verso de Dante Alighieri, que foi hospedado pela família Scaligeri, na cidade de Verona, entre 1303 e 1304. Alighieri citou a disputa no $6^{\circ}$ poema do Purgatório, versos 106/108: "Venham ver Montecchi e Cappelletti/Monaldi e Filippeschi, cujas brigas não têm solução: tristes cores, e muitas desconfianças!". Um detalhe da história de Da Porto diverge da versão de Shakespeare: a sorte da protagonista que coloca fim a própria vida, trancando a respiração e não com o punhal cravado em seu corpo.

A obra tem publicação póstuma no ano de 1531, mas com indícios de ter sido escrita em 1524, conforme testemunho de uma carta recebida pelo cardeal Pietro Bembo, com data de 9 de junho daquele ano, em resposta a uma carta de Da Porto, conforme indicação na tese de Fontanili.

A novela escrita por Da Porto foi logo recuperada em um poema na oitava rima atribuído a Gherardo Boldieri e, em 1554, em uma obra de Matteo Bandello. A história logo teve grande fama em toda a Europa, com versões escritas pelo inglês Arthur Brooke em 1562, William Painter, em 1569, e o espanhol Felix Lope de Vega, em 1590.

Uma versão da tragédia dos dois amantes, registrada em poema anônimo, foi atribuída a Gherardo Boldieri (1497-1571) com o título O trágico amor de dois apaixonados Julieta e Romeu escrito em oitava rima por Clizia, nobre de Verona, e Ardeu, publicado em Veneza, no ano de 1553. O episódio de Romeu e Julieta é colateral no poema, uma vez que os protagonistas da tragédia são Clizia e Ardeo. A jovem, após quatorze anos de impedimentos, premedita o suicídio e, ao cometê-lo narra a história de Romeu e Julieta como exemplo.

Para além do contexto italiano, foi sucesso a versão de Bandello, traduzida para o francês por obra de Pierre Boisteau, em 1559. Nessa tradução, o autor promove modificações, como por exemplo um diálogo entre Romeu e uma namorada que conhecera antes de Julieta; Julieta aceita se casar com o conde de Lodrone; a morte da protagonista se dá com uma punhalada e não por ter trancado a respiração. 


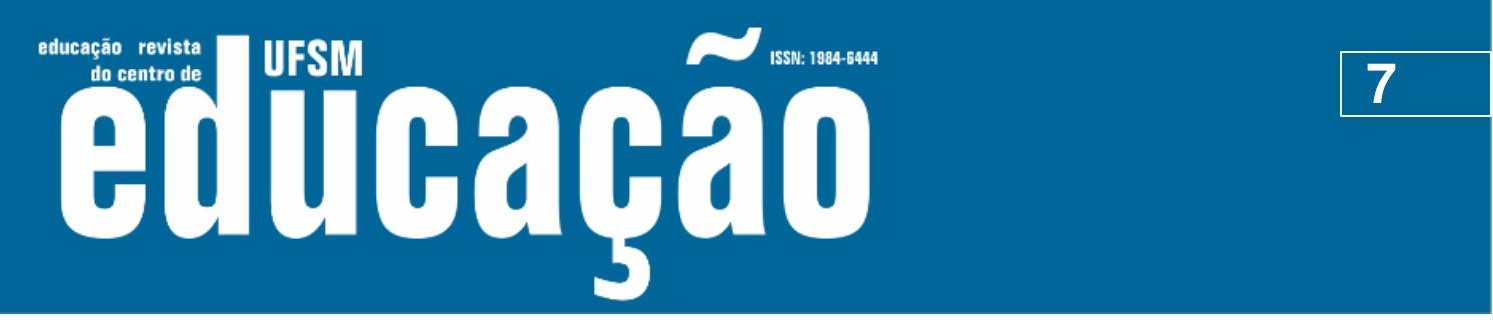

ISSN: 1984-6444 | http://dx.doi.org/10.5902/1984644438119

Na sequência da versão francesa, Brooke a traduz com o título A trágica história de Romeu e Julieta. Sua transposição ampliou o papel da dama de companhia de Julieta, criando cenas cômicas e vulgares desta, e o personagem Marcuccio tem o nome modificado para Mercuzio, conforme os estudos de Fontanili (2015), que, apoiando-se em Villari (2011), explica:

Sucessivamente, entre os anos 1594-1595 Shakespeare, dramaturgo inglês, havia composto a versão de Romeu e Julieta, a mais conhecida dentre as que chegaram aos dias atuais, apresentada pela primeira vez para a rainha Elisabete no inverno de 1595-1596 e publicada em 1597.

Em 1599, ele publicou uma segunda edição ampliada e corrigida, cujo título foi "A nobre e lamentável tragédia de Romeu e Julieta", corrigida e atualizada com partes da história recitada em público pelos servos do honorável lorde Ciambellano. Dessa versão foi feita a definitiva datada de 1623 (Villari, 2011, p. 8 apud. Fontanili p. 36 - Tradução nossa) $)^{3}$.

O trágico enredo de Romeu e Julieta, mais do que um processo das transformações das escritas (segundo o tempo e o espaço) abre a possibilidade para uma história contextualizada das mentalidades. É possível perceber a maneira como as pessoas entendiam o mundo, como organizavam a realidade em suas mentes e a expressavam em seu comportamento por meio de narrativas. Aliás, nesse sentido, Darnton (1988) alerta que as pessoas, "[...] em vez de tirarem conclusões lógicas, pensam em coisas, ou com qualquer material que sua cultura lhes ponha à disposição, como histórias ou cerimônias".

Ao impacto causado pela tragédia dos amantes, mais do que um julgamento sobre a veracidade da mesma, sobre a veracidade da existência dos personagens, é fundamental associar o tempo histórico dos séculos XIV e XV com a pandemia da peste negra. Um século em que a doença reduziu drasticamente a população no continente europeu. Contos populares como do amor entre Romeu e Julieta não teriam uma função pedagógica na construção das sensibilidades entre casais? Afinal, era necessário povoar novamente aqueles territórios. Em tempos de restrita autonomia para mulheres escolherem o casamento e, especialmente com o homem amado, tais narrativas poderiam ser veículo para construção de mentalidade singular sobre o amor. Na metamorfose literária do clássico, fica perceptível a restrição às escolhas para o mundo feminino ao ponto de a melhor alternativa ser o suicídio a viver com um marido não desejado. Sinal dos tempos de um Renascimento que se 


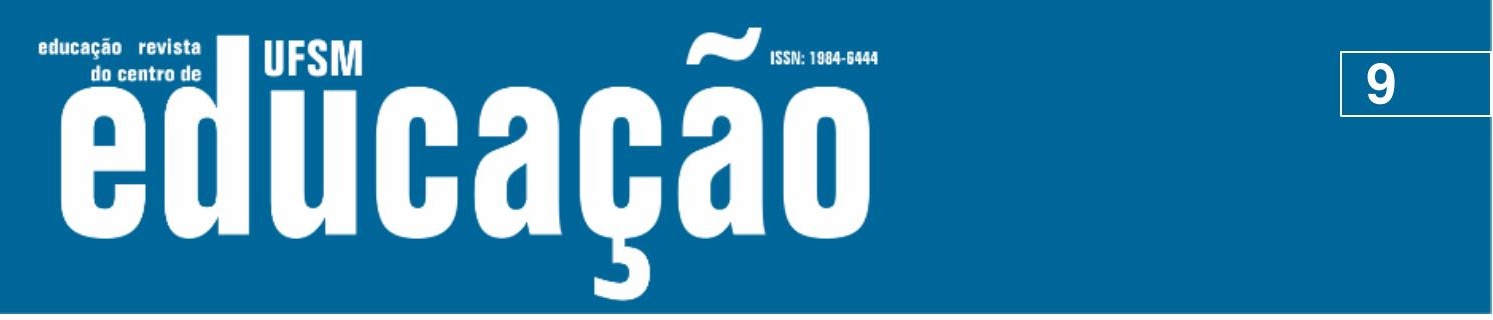

ISSN: 1984-6444 | http://dx.doi.org/10.5902/1984644438119

história fonte. O cenário, cidade de Verona, na Itália, caracteriza o estilo arquitetônico onde a narrativa ocorre, assim como as figuras das páginas seguintes, que também apresentam esses elementos. A imagem de Romeu e Julieta envoltos pela lua - o que é sugerido pelo círculo mais claro que os envolve - está centralizada na capa e imprime tons românticos à cena, antecipando a proposta do título.

Na segunda capa e na folha de guarda, há imagens do cenário onde a história acontece, predominando tons azuis, como se o autor quisesse acolher o leitor ao prepará-lo para a leitura. O conjunto posto sinaliza o ambiente noturno, antecipando, em parte, a temporalidade da narrativa. Já a página 4 (Fig. 2) é formada com esboço de imagens (ainda sem cor) que compõem a narrativa e revelam aspectos do processo de elaboração de uma $\mathrm{HQ}$, compartilhando com o leitor aspectos da fabricação do livro.

Figura 2 - Esboço de figuras presentes na obra

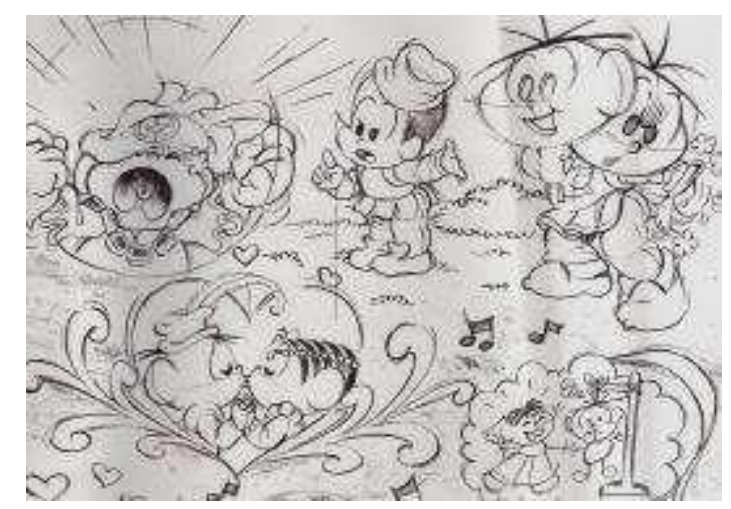

Fonte: Sousa (2009)

A abertura da narrativa (Fig. 3), na página 5, mostra Romeu, representado por Cebolinha - de frente para o leitor -, convidando os interlocutores a virarem as páginas do exemplar. A fala característica do personagem é mantida, ou seja, com as trocas do "r" pelo "I": "O AMADO PÚBLICO NO TEATLO TOCA A SINETA... E A EMOÇÃO É TANTA, OLA, PUXA... VAMOS LEPLESENTAR LOMEU E JULIETA... EU SELEI O TAL, E A OUTLA, A GOLDUCHA... EIS MEU ÚLTIMO AVISO, LOMANTISMO NÃO VAI FALTAR, MAS TAMBÉM PLEPALE O LISO, QUANDO A PÁGINA VILAR...". OS termos em que há troca da consoante "r" pela "l" são grafados em negrito, a fim de 


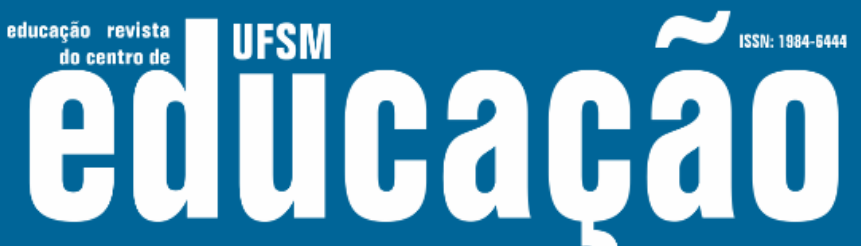

ISSN: 1984-6444 | http://dx.doi.org/10.5902/1984644438119

apontar o desvio de linguagem.

Figura 3 - Abertura da narrativa

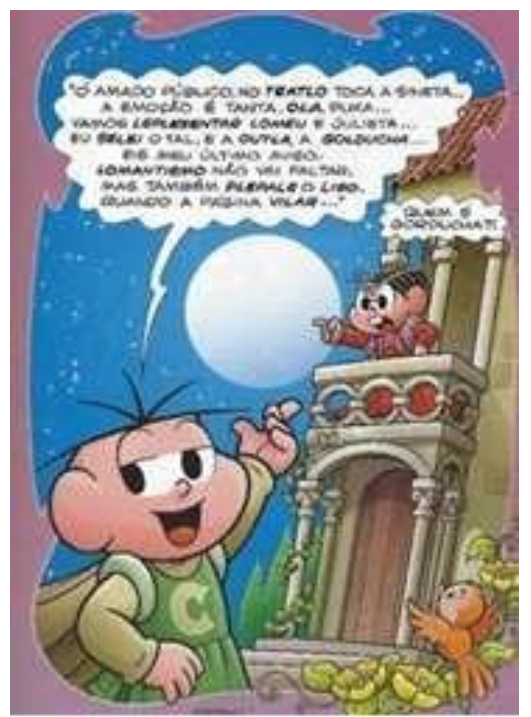

Fonte: Sousa (2009)

Ao dirigir-se ao leitor iniciante, didaticamente, a narrativa é dividida em 4 partes: capítulo 1 - "Montéquio e Capuleto"; capítulo 2 - "A cena do balcão"; capítulo 3 - "O casamento"; e capítulo 4 - "E o amor nasceu". Ao contrário da obra original, em que o final é trágico, a história, na versão da Turma da Mônica, cria desfecho feliz e com muitos momentos divertidos que agradam o público ao qual o livro se destina. Durante todo o percurso da narrativa adaptada, evidenciam-se semelhanças com a história original. Porém, para que a relação entre as histórias se efetive, é necessário conhecimento prévio sobre o enredo original escrito por Shakespeare.

O texto fonte, como já foi apontado, relata a história transcorrida, em Verona, na Itália, por volta do século XIV, em que duas famílias inimigas, Montéquio e Capuleto, vivem em disputa. A rivalidade estende-se a parentes e a criados, apesar dos apelos de paz feitos pelo nobre que administrava a cidade. O conflito da tragédia shakespeariana inicia a partir de um baile de máscaras, na casa dos Capuletos, quando Romeu Montéquio e Julieta Capuleto se conhecem. Os jovens apaixonam-se e, ao descobrirem que pertencem a famílias inimigas, desesperam-se. Assim, com a 


\section{Tusm 2

ISSN: 1984-6444 | http://dx.doi.org/10.5902/1984644438119

ajuda do Frei Lourenço, resolvem casar-se em segredo, e o destino final permanece trágico.

$\mathrm{Na}$ adaptação em estudo, a integração entre os dois mundos - dos protagonistas de Shakespeare e daqueles de Mauricio de Sousa - é constante. Consideramos que a $\mathrm{HQ}$ em questão tem poder atrativo aos pequenos, tanto pela forma divertida como o enredo se desenrola quadro a quadro, como pela intertextualidade que compõe a obra. De acordo com Marly Amarillha, a intertextualidade pode assumir o propósito da "[...] diversão, desconstruindo padrões estáveis de idéias (sic.), argumentos, atitudes que gera o riso" (2009, p. 60). No título analisado, alguns elementos da trama são mantidos, mas outros, conforme os interesses do público visado e traços característicos dos personagens da Turma da Mônica, são alterados.

$\mathrm{Na}$ história adaptada, predomina o humor - constante nas narrativas de Mauricio de Sousa, e o desfecho é ajustado à perspectiva dos leitores, desconstruindo a história original, cujo final é trágico. A subversão do desfecho, por sua vez, é coerente tanto com a ação dos personagens da Turma da Mônica quanto com os interesses de leitores potenciais.

Ao longo da narrativa, a história desenvolve-se subvertendo a opção pelos requadros $^{4}$, que geralmente envolvem cada cena das histórias em quadrinhos e molduram a sequência de fatos. As imagens que seguem (Fig. 4) demonstram alguns exemplos, em que as figuras ora mostram-se dentro de moldura que lembra o papiro, ora dentro de arco que sugere uma porta: 


\section{T usm

ISSN: 1984-6444 | http://dx.doi.org/10.5902/1984644438119

Figura 5 - Imagem dos castelos abre a história.

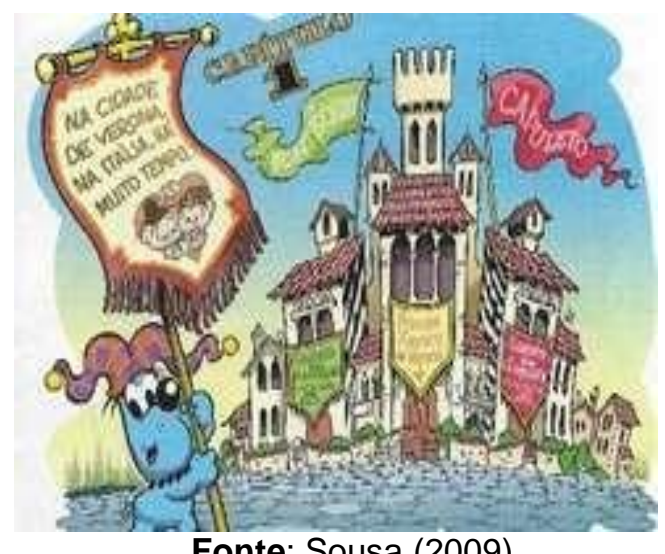

Fonte: Sousa (2009)

$\mathrm{Na}$ abertura da $\mathrm{HQ}$ (Fig. 5), a imagem representa o que seria a cidade de Verona, porém sem o requadro, reafirmando ao leitor a sensação de a narrativa abranger um espaço mais amplo. Nessa mesma página, os personagens, mais adiante, aparecem nas janelas de suas residências, reiterando elementos arquitetônicos do cenário original, onde ocorre o enredo de Shakespeare.

O dinamismo da narrativa constitui-se pelo emprego de diversos recursos. Para intensificar a ação (Fig. 6), fundos distintos envolvem os personagens, conferindo alternância de formas, cores, traçados e contornos. Em uma das cenas, por exemplo, em que é enfatizada a paixão entre Romeu e Julieta, é utilizado o requadro em formato de coração (primeira imagem da página 13), sugerindo ao leitor sensações de amor, tema do enredo. Logo abaixo, no entanto, a fúria de Mônica (não de Julieta) é referendada pelo requadro com traços pontiagudos ao redor (terceira imagem da Fig. 6). O traçado denteado indica ação emocionalmente explosiva, assim como a letra em negrito dentro do balão revela o estado emocional da personagem. Cores, formas e posturas expressam, portanto, estado de tensão, relacionado à sonoridade áspera associada à transmissão de som (EISNER, 2012, p. 48). De acordo com Eisner (2012), este estilo de requadro contribui para aumentar a percepção do leitor quanto à tensão que envolve os personagens. 


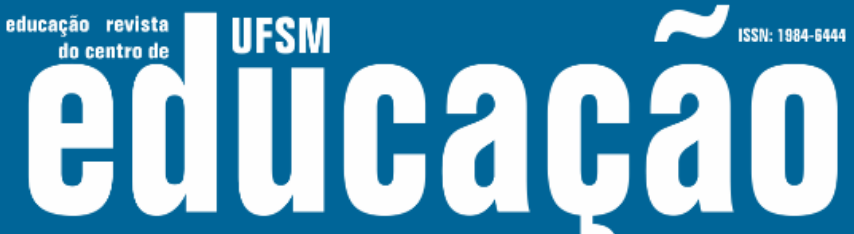 \\ 3}

ISSN: 1984-6444 | http://dx.doi.org/10.5902/1984644438119

Figura 6 - Encontro de Romeu e Julieta

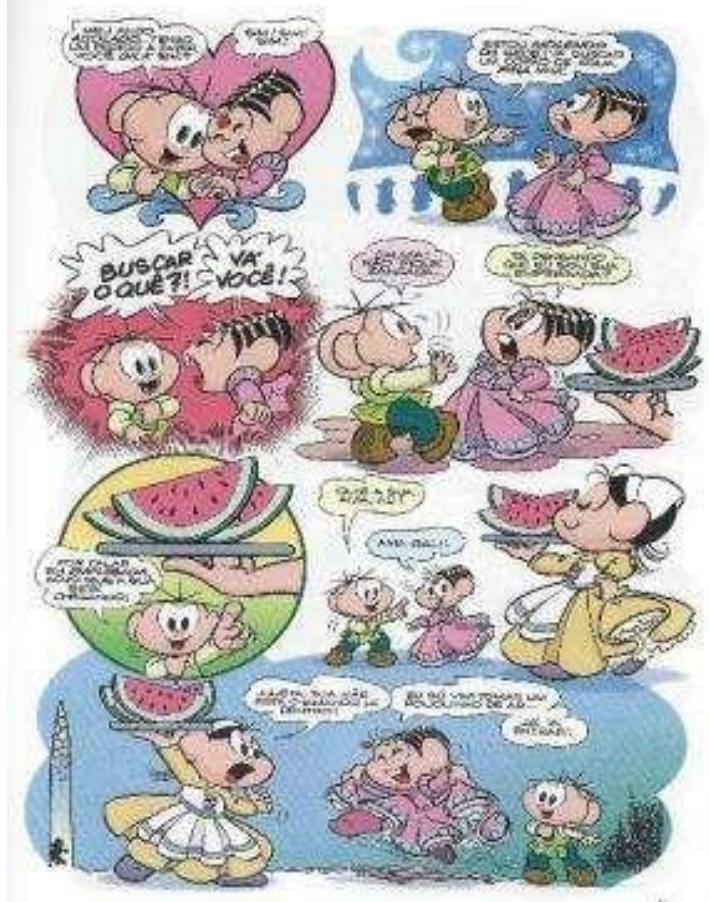

Fonte: Sousa (2009)

A passagem de tempo (Fig. 7) também pode ser percebida nos cenários da narrativa. Alguns elementos caracterizam essa alteração, como a lua que muda de posição e de tamanho, assim como o sol que, em alguns momentos, ilumina a cena. A sequência de ações, os diálogos entre os personagens e a mudança nas cenas podem ser observados pelo leitor, auxiliando-o a identificar o tempo da história. A marcação temporal é, pois, percebida pelos tons do cenário e pela ação dos personagens.

Figura 7 - Sinais da passagem do tempo
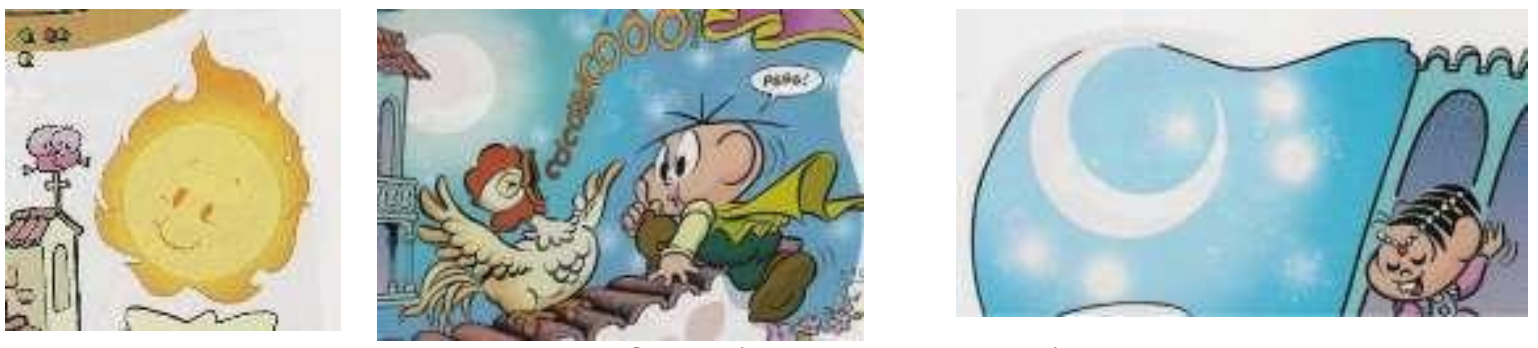

Fonte: Sousa (2009, p. 40, 18 e 26). 


\section{Ellithaß̧ã́}

ISSN: 1984-6444 | http://dx.doi.org/10.5902/1984644438119

Figura 8 - Personagens multiplicados

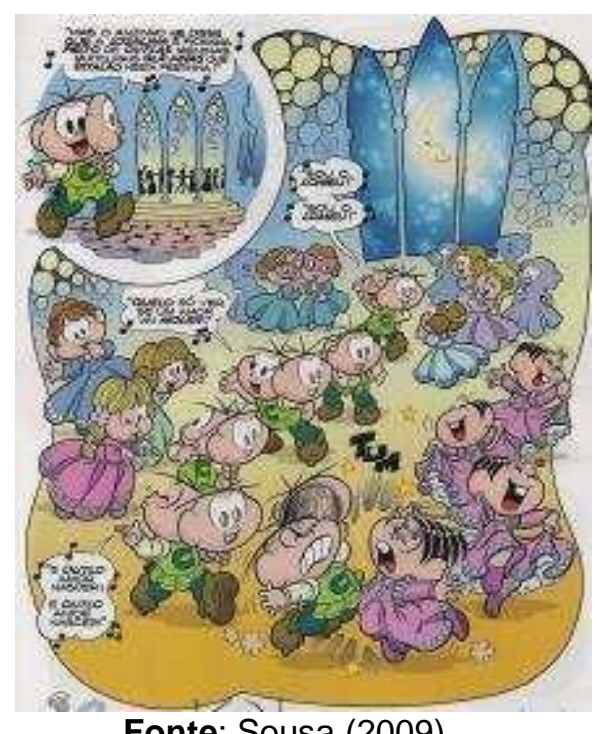

Fonte: Sousa (2009)

Figura 9 - Ação e humor no casamento

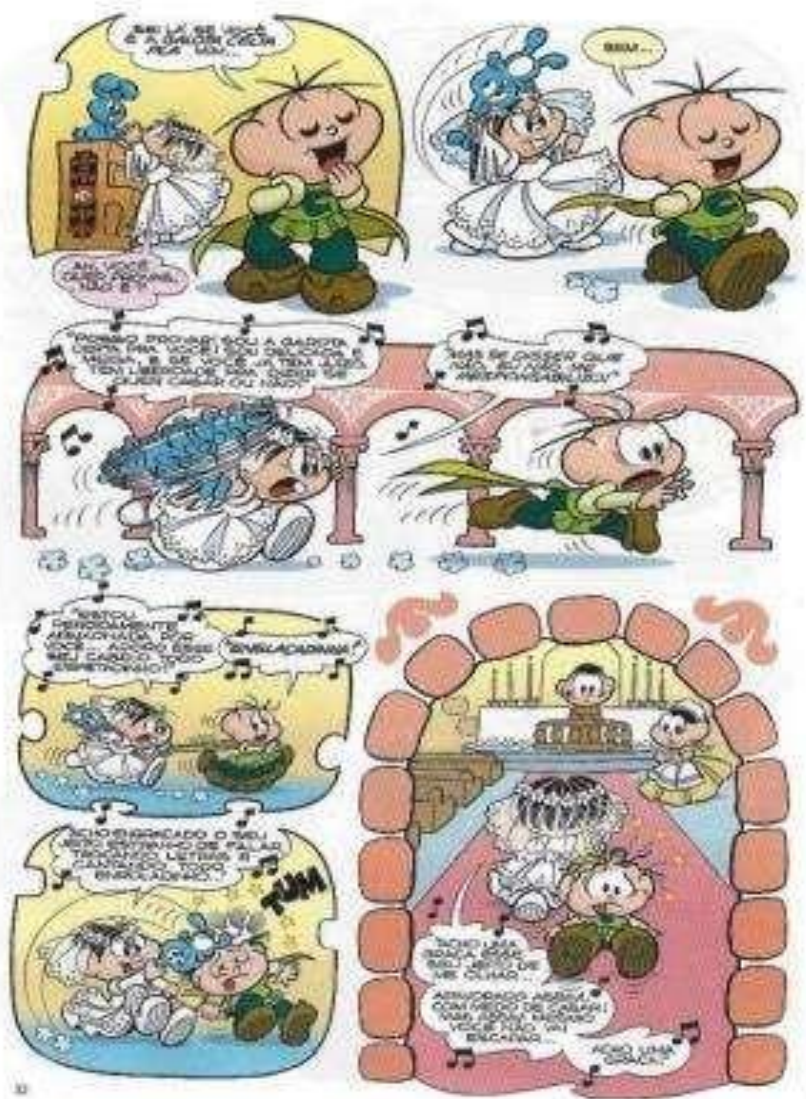

Fonte: Sousa (2009) 


\section{T usm

ISSN: 1984-6444 | http://dx.doi.org/10.5902/1984644438119

Figura 10 - Romeu com expressão de dor e de pavor.
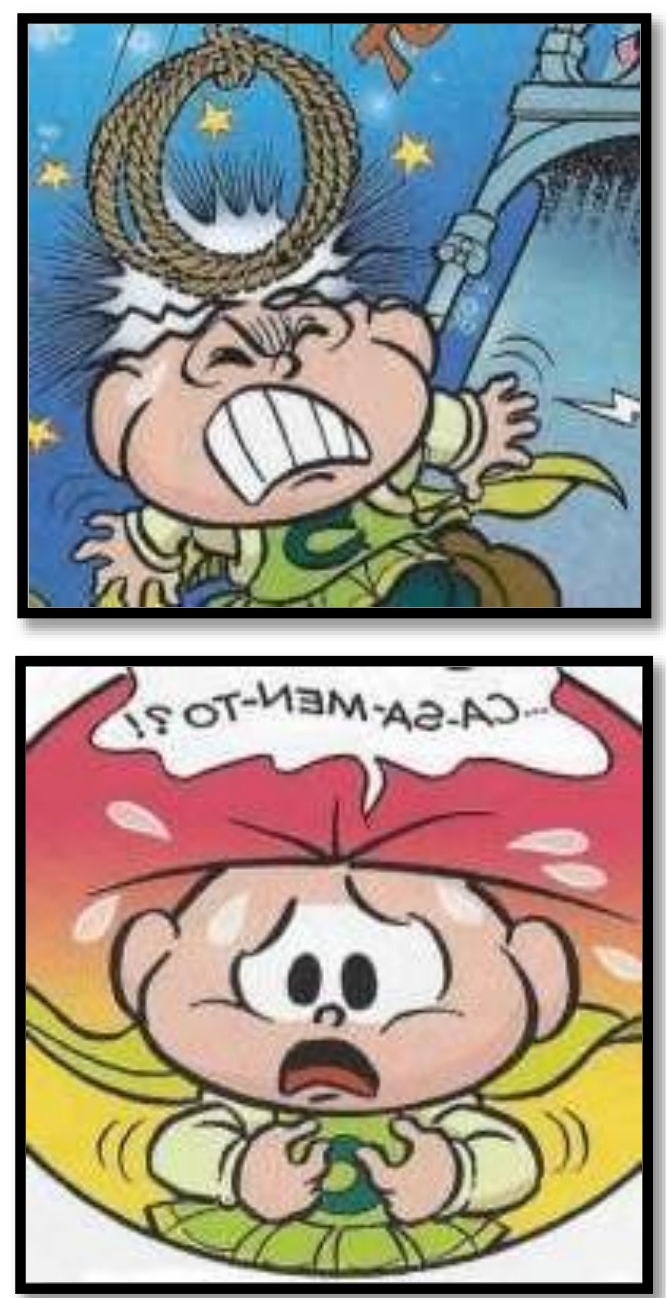

Fonte: Sousa (2009, p. 23 e 25).

Nesse ponto, Eisner alerta que no material impresso, diferentemente do cinema ou do teatro, "[...] o artista tem que sintetizar numa única postura uma centena de movimentos intermediários de que se compõe o gesto. Essa postura selecionada deve expressar nuança, servir de suporte ao diálogo, impulsionar a história e transmitir a mensagem." (2012, p. 104). A Turma da Mônica potencializa a mensagem intencionada, a partir das posturas dos personagens, seus olhares, gestos e atitudes.

A reunião de sistemas verbal e visual constituem a narrativa, de modo que: 


\section{F WEM Eifloará

ISSN: 1984-6444 | http://dx.doi.org/10.5902/1984644438119

Quanto aos tipos de quadros, a história desenvolve-se subvertendo a opção pelos requadros, com uma concepção de que o espaço é ilimitado. Os diferentes traçados indicam ações com distintas manifestações das emoções, como, por exemplo, o traçado denteado para uma atitude emocionalmente explosiva, assim como a letra em negrito dentro do balão revela o estado emocional da personagem. Cores, formas e posturas expressam, portanto, estado de tensão, relacionado à sonoridade áspera associada à transmissão de som.

Mauricio de Sousa ambientou a história no cenário da cidade de Verona, como no texto de Shakespeare. Os diálogos entre os personagens da HQ são em parte aqueles do texto original, mas com a visualidade imprimindo tom humorístico às cenas. A compreensão das sutilezas dos elementos presente na narrativa das $\mathrm{HQ}$ possibilita ao leitor viver, ou não, uma experiência estética de leitura.

A marcação da passagem do tempo é sutil e ocorre por meio da visualidade, como o requadro com o plano de fundo em cor preto com uma grande lua. Quanto aos personagens, as vestimentas usadas intensificam a identificação entre os personagens shakespearianos e do quadrinista brasileiro, predominando roupas clássicas. Assim, é possível dizer que na adaptação em estudo, é constante a integração entre o mundo shakespeariano e o de Mauricio de Sousa.

Cada tempo, cada lugar, cada público visado contribui para ajustar um determinado conflito à situação de enunciação. Se o conflito é contado oralmente recebe certas nuances. Se é impresso, vale-se das tecnologias da época e do perfil do público eleito. Ou seja, as histórias vão se metamorfoseando. Ao transpor um conflito para uma $\mathrm{HQ}$ entram elementos próprios desse gênero como o emprego de balões, a disposição dos quadros na página conforme o ritmo da narrativa, alterações de pontos de vista marcados por recurso de enquadramento, que ora aplica o plano aproximado ora o panorâmico, sinalizando movimento.

$\mathrm{Na}$ narrativa adaptada, predominam aspectos lúdicos dos personagens da Turma da Mônica, porém sem apagar a essência da história original escrita por Shakespeare. A adaptação transpõe alguns momentos da obra original, como os nomes das famílias envolvidas no enredo, os cenários, assim como a caracterização dos personagens e de suas vestimentas de acordo com a época e o local da história 


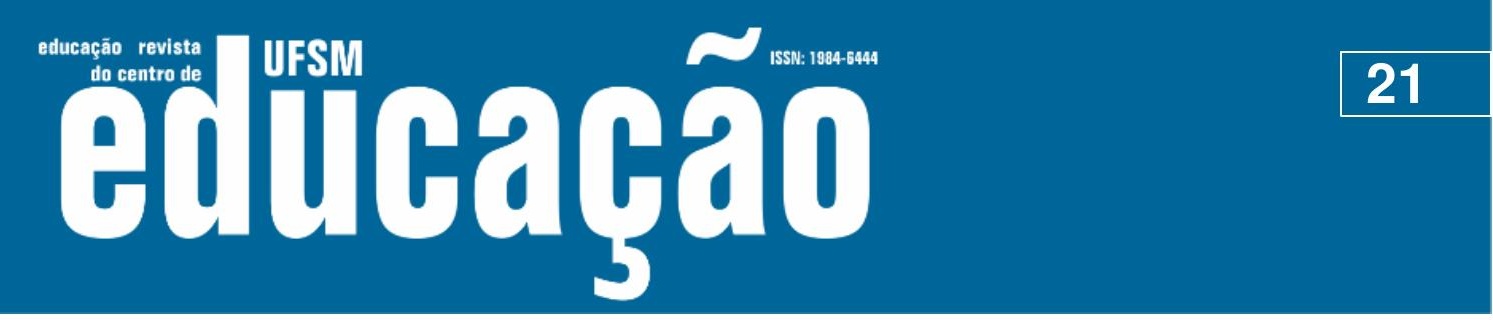

ISSN: 1984-6444 | http://dx.doi.org/10.5902/1984644438119

fonte.

Mesmo que a adaptação seja uma manifestação textual cujo propósito é tornar acessível ao leitor atual um texto que lhe é distante, espacial ou temporalmente, há elementos contextuais sem os quais a recepção da obra ficaria comprometida. Entendemos, portanto, que o repertório do leitor é fundamental para a concretização do título, pois se não tiver conhecimento acerca de dados do enredo da peça original, terá restrições para compreender, por exemplo, o porquê das vestimentas ou, então, as sutilezas da arquitetura que compõem o cenário.

\section{Referências}

AMARILHA, Marly. História em quadrinhos e literatura: leveza e drama na formação do leitor. Revista Educação em Questão, Natal, v. 36, n. 22, p. 56-73, set./dez. 2009.

DARNTON, Robert. O grande massacre de gatos, e outros episódios da história cultural francesa. Rio de Janeiro: Graal, 1986.

EISNER, Will. Quadrinhos e a arte sequencial: princípios e práticas do lendário cartunista. São Paulo: Martins Fontes, 2012.

FONTANILI, Francesca. Casa di Giulietta, metamorfose di una demora storica: reale e ideale si uniscono nel presente. Tese em Museologia Archeologica. Alma Mater Studiorum, Università di Bologna.

RAMOS, Flávia Brocchetto; PANOZZO, Neiva Senaide Petry. Modalidades narrativas: cantos lusitanos em quadrinhos. Educação, Porto Alegre, v. 35, n. 3, p. 352-361, set./dez. $2012 . \quad$ Disponível em: http://revistaseletronicas.pucrs.br/ojs/index.php/faced/article/view/11766/8392.

Acesso em: 26 set. 2014.

SOUSA, Mauricio de. Turma da Mônica - Romeu e Julieta. Barueri, SP: Panini Brasil, 2009.

\section{(C) $(1) \Theta$}

This work is licensed under a Creative Commons Attribution-NonCommercial 4.0 International (CC BY-NC 4.0) 
